\title{
RETROACTIVIDAD DE LAS CAPITULACIONES MATRIMONIALES AL MOMENTO DE CELEBRACIÓN DEL MATRIMONIO. COMENTARIO DE LA SAP DE MURCIA, DE 23 ABRIL 2020
}

\author{
RETROSPECTIVE EFFECT OF THE MATRIMONIAL PROPERTY \\ AGREEMENT. COMMENTARY OF THE JUDGMENT OF \\ APPEAL COURT OF MURCIA, 23TH MAY 2018.
}

\author{
JULIANA RODRÍGUEZ RODRIGO \\ Profesora Titular de Derecho Internacional Privado \\ Universidad Carlos III de Madrid \\ ORCID ID: 0000-0002-5896-983X
}

Recibido: 15.12.2020 / Aceptado: 12.01.2021

DOI: https://doi.org/10.20318/cdt.2021.6015

\begin{abstract}
Resumen: La sentencia de la Audiencia Provincial de Murcia, objeto de comentario, resuelve un litigio que enfrenta a una pareja en relación con el régimen económico matrimonial respecto de un bien inmueble adquirido por el esposo. Según este, el bien debería inscribirse bajo el régimen de separación de bienes y considerarse bien privativo suyo. Según la mujer, el inmueble fue adquirido por el esposo mientras el régimen económico del matrimonio era el de gananciales y, por ello, el bien debería aparecer inscrito como común de ambos cónyuges.

El elemento de discusión en el caso es el otorgamiento de unas capitulaciones matrimoniales, cuatro después de la celebración de la unión conyugal, según las cuales el matrimonio se contrajo bajo el régimen de sociedad de gananciales. Esto es lo que alega la esposa para sostener que el bien inmueble debe ser ganancial. El marido, en cambio, argumenta que la ley aplicable al régimen económico de la pareja es el Derecho argelino y, por tanto, la separación de bienes.

La Audiencia Provincial de Murcia, sin justificar la resolución del caso, establece que, como en las capitulaciones matrimoniales se dice que el matrimonio se celebró bajo el régimen de sociedad de gananciales y el inmueble se adquirió antes del otorgamiento de las mismas, dicho bien debe considerarse ganancial porque no es hasta la fecha de celebración de las capitulaciones cuando el régimen económico de la pareja pasa a ser el de separación de bienes. Con esta solución del supuesto, estudiamos en este trabajo, fundamentalmente, los posibles efectos retroactivos de las capitulaciones matrimoniales.

Palabras clave: régimen económico matrimonial, artículo 9.2 CC, artículo 9.3 CC, Reglamento 2016/1103, irretroactividad de las capitulaciones matrimoniales, publicidad registral del régimen económico matrimonial.
\end{abstract}

Abstract: The judgment of the Appeal Court of Murcia, subject to comment, resolves a dispute faced by a couple in relation to the matrimonial property regime regarding a property acquired by the husband. Accordingly, the property must be registered under the property separation regime and be considered own property. According to the woman, the assets were acquired by the husband while the economic regime of the marriage was that of the common assets and, therefore, the assets should appear registered as common to both spouses. The element of discussion in the case is the granting of a marriage property agreement, celebrated four years after of the marriage, according to which the ma- 
rriage was contracted under community property. This is what the wife claims to hold that the property must be jointly owned. The husband, on the other hand, argues that the law applicable to the economic regime of the couple is Algerian law and, therefore, the separation of property. The Appeal Court of Murcia, without justifying the resolution of the case, establishes that, as in the matrimonial property agreement it is said that the marriage was celebrated under community property regime and the property was acquired before the granting of the same, the asset must to be considered common because it is not until the date of the matrimonial property agreement that the couple's economic regime becomes that of patrimonial separation. With this solution, we study, fundamentally, the possible retroactive effects of matrimonial property agreements.

Keywords: matrimonial property regime, article 9.2 CC, article 9.3 CC, Regulation 2016/1103, non-retroactivity of matrimonial property agreement, registry advertising of the matrimonial property regime.

Sumario: I. Introducción; II. Hechos del caso; III. Problemas que plantea la sentencia; IV. Capitulaciones matrimoniales; 1 . Regulación jurídica; 2. Validez de las capitulaciones matrimoniales; A. Ley aplicable; B. Carácter retroactivo; V. Otorgamiento de capitulaciones ante autoridad consular española en el extranjero; VI. Publicidad registral.

\section{Introducción}

1. En la sentencia objeto de comentario, la Audiencia Provincial de Murcia se pronuncia en un recurso de apelación, presentado contra una sentencia del Juzgado de Primera Instancia e Instrucción $\mathrm{n}^{\mathrm{o}} 3$ de Molina de Segura, por parte de un cónyuge que reclama que un bien inmueble, inscrito bajo el régimen de gananciales, es privativo suyo.

En el caso, el apelante contrajo matrimonio con la apelada el 3 de junio de 2003, en Argelia. Fijaron su residencia en Argel. Posteriormente, el 30 mayo 2007, otorgaron capitulaciones matrimoniales ante el Cónsul General de España en Argel.

2. La sentencia de la Audiencia Provincial no es clara en algunos aspectos, bien porque contiene algún error en las fechas, bien porque no explica de manera razonada la solución a la que llega ${ }^{1}$. La decisión final del tribunal es que el bien objeto del litigio no es privativo por la razón de que se compró antes del otorgamiento de las capitulaciones en las que se dice que el matrimonio se contrajo en régimen de gananciales ${ }^{2}$.

3. Las cuestiones que van a ser tratadas en este trabajo con más detalle son las dos siguientes. En primer lugar, expondremos los hechos de la resolución judicial, explicando los fundamentos de Derecho

\footnotetext{
${ }^{1}$ En cuanto a las fechas, en la resolución judicial se indica lo siguiente:

"En fecha 19 de julio de 2007 se comunicó a D. Jacobo, tras haber pujado por algunos bienes, terrenos y viviendas a través de la página web de la Agencia Estatal de la Administración Tributaria, que se le asignó una vivienda situada en Las Torres de Cotillas (Murcia), y que disponía de un plazo de 15 días para abonar 35.000 euros correspondientes al precio de adquisición.

El pago del precio se efectuó el 2 de agosto de 2006 desde la cuenta corriente ...." (FD Tercero).

Como se puede comprobar, hay un error en el año en el que acontecen los hechos relatados por el tribunal. Se ha de entender que el año correcto es 2006 para que tenga sentido que las capitulaciones matrimoniales, otorgadas en mayo 2007, cambian el régimen matrimonial de gananciales por el de separación de bienes y que, como esta modificación se produce después de la adquisición del bien por parte del esposo, dicho inmueble se encuentra sometido al primero de los regímenes mencionado, el subsistente en ese momento, el de gananciales.

2 "Ninguna controversia hay en que la vivienda situada en Las Torres de Cotillas, finca $n^{\circ}$ NUM012 fue inscrita en el Registro de la Propiedad de Molina de Segura el 1 de febrero de 2007, perteneciendo el $100 \%$ del pleno dominio a $D^{a}$ Virginia y a D. Jacobo, por título de adjudicación administrativa con carácter presuntivamente ganancial (folio 28). Y tampoco admite discusión que el 30 de mayo de 2007 los litigantes otorgaron escritura de capitulaciones matrimoniales ante Da Rosario, Cónsul General de España en Argel, en funciones notariales, en la que se decía que la Sra. Virginia y el Sr. Jacobo contrajeron matrimonio civil el 3 de junio de 2003 bajo el régimen legal de gananciales. Por tanto no fue hasta el 30 de mayo de 2007 que los litigantes pasaron a regirse por el régimen de separación de bienes" (FD Tercero).
} 
que han justificado el fallo del tribunal. En segundo lugar, abordaremos las consecuencias que puede tener el cambio de la ley aplicable al régimen económico matrimonial, en el sentido de si dicha modificación podría tener efectos retroactivos al momento de la celebración del enlace.

\section{Hechos del caso}

4. De los datos que aparecen en la sentencia de la Audiencia Provincial de Murcia sólo podemos conocer los siguientes hechos relevantes. El litigio surge en relación con un matrimonio celebrado en Hydra (Argelia) el día 3 de junio 2003. La pareja fijó su residencia, tras el enlace, en Argel. No otorgaron capitulaciones matrimoniales hasta el 30 de mayo 2007. En estas capitulaciones se hace constar que el matrimonio se contrajo bajo el sistema de gananciales y que, por tanto, a partir de esta fecha de 30 de mayo 2007 es cuando el régimen aplicable es el de separación de bienes (FD Tercero).

5. La controversia se plantea cuando el 1 de febrero de 2007 se inscribe un bien inmueble como propiedad por mitades de ambos cónyuges y el esposo litiga porque considera que dicho bien es privativo de él. El marido lo adquirió y reclama que, en virtud del artículo $9.2 \mathrm{CC}$, la ley aplicable a su régimen económico matrimonial, en ese momento de adquisición del bien, era el ordenamiento argelino; según el cual, rige la separación de bienes.

6. Sin embargo, la Audiencia Provincial de Murcia estima que, como la adquisición el bien se produjo antes del otorgamiento de las capitulaciones matrimoniales, el bien es ganancial y, por tanto, de los dos cónyuges. Todo ello porque, como se ha mencionado antes, en los capítulos se indica que el matrimonio se contrajo en régimen de gananciales.

\section{Problemas que plantea la sentencia}

7. Son dos los problemas que suscita la resolución judicial. Por un lado, no queda claro si los cónyuges contrajeron matrimonio pactando el régimen de gananciales como aplicable a su relación económica. Esto es debido a que las primeras y únicas capitulaciones de las que se habla en la sentencia son las de fecha de 30 de mayo 2007, cuatro años después de la celebración del enlace.

Lo anterior nos lleva a pensar que, puesto que el tribunal indica que en las capitulaciones matrimoniales se hace constar que el matrimonio se celebró bajo el régimen de gananciales, los cónyuges han podido pactar este sistema en el año 2007 y hacerlo aplicable desde el momento de la celebración del matrimonio. Lo cual nos plantea el segundo problema, la posible retroactividad de las capitulaciones matrimoniales.

\section{Capitulaciones matrimoniales}

\section{Regulación jurídica}

8. La norma de conflicto que debe aplicar el tribunal español para conocer la ley rectora del régimen económico matrimonial de la pareja es el artículo 9.2 CC. Así es, pese a que en el ordenamiento español existe el Reglamento 2016/1103, esta norma europea, en lo que a ley reguladora se refiere, se aplica a los matrimonios celebrados después del 29 de enero de 2019 (art. 69.3) 3 $^{3}$ Por lo tanto, la unión

\footnotetext{
${ }^{3}$ Reglamento (UE) 2016/1103, del Consejo, de 24 de junio de 2016, por el que se establece una cooperación reforzada en el ámbito de la competencia, la ley aplicable, el reconocimiento y la ejecución de resoluciones en materia de regímenes económicos matrimoniales, DOUE L183, de 8 julio 2016.

Vid., en relación con el ámbito de aplicación temporal de la norma, H. PÉroz/E. Fongaro, Droit international privé patrimonial de la famille, $2^{\mathrm{a}}$ ed., Lexis Nexis, Paris, 2017, pp. 125-126; I. BARrière BrousSE, "Le patrimoine des couples interna-
} 
objeto del litigio no se encuentra dentro de su ámbito de aplicación y esta normativa supranacional no puede ser utilizada por el juez español para resolver el caso.

9. Según el precepto mencionado de producción interna, el artículo $9.2 \mathrm{CC}$, la ley aplicable al régimen económico matrimonial es la ley personal común de los cónyuges, al tiempo de celebración del enlace. La ley personal se corresponde con la ley nacional ${ }^{4}$.

Presumimos que la nacionalidad de los contrayentes al tiempo de contraer el matrimonio es la que tienen en la actualidad, cuando se plantea el litigio. Con esta premisa, la pareja no tiene nacionalidad común porque el esposo es español y la mujer es argelina.

10. En defecto de nacionalidad común, el artículo 9.2 CC indica que la ley aplicable será la elegida en documento auténtico, antes de la celebración del matrimonio. La elección debe realizarse entre la ley de la nacionalidad o de residencia habitual de cualquiera de los contrayentes, en el momento de la elección ${ }^{5}$.

Con los datos del caso, parece que la pareja no ha ejercido la autonomía de la voluntad antes de la celebración del matrimonio, al menos, no consta en la sentencia que el matrimonio haya elegido ley aplicable a su relación antes de la celebración de las nupcias.

11. En tercer lugar, en defecto de las anteriores conexiones, la ley aplicable será la del Estado en el que la pareja tenga su residencia habitual inmediatamente después de la celebración del matrimonio ${ }^{6}$. Esta conexión sí concurre. Los esposos fijan en Argel su residencia después del enlace. Presumimos, en este caso y ante la falta de datos al respecto, que se trata de residencia habitual. Un elemento que nos ayuda a establecer esta premisa es que la capitulaciones matrimoniales, otorgadas cuatro años después de la celebración de las nupcias, se realizan ante el Cónsul General de España en Argel, por lo que podemos entender que la pareja sigue residiendo en el mismo lugar -Argel- desde el comienzo de su matrimonio.

$\mathrm{Si}$ esto es así, la ley aplicable a su régimen económico matrimonial sería la argelina. Según la cual, tal como indica la sentencia, el matrimonio se rige por el sistema de separación de bienes (FD Primero).

tionaux dans l'espace judiciaire européen. Les règlements européens du 24 juin 2016 relatifs aux régimes matrimoniaux et aux effets patrimoniaux des partenariats enregistrés", JDI Clunet, nº 2, 2017, p. 493; L. UsunIER, "Libre, mobile, divers: le couple au miroir du droit international privé de l'Union européenne", Revue Trimestrielle de droit civil, $\mathrm{n}^{\circ}$ 4, 2016, pp. 808-809; C. Nourissat/M. ReVILlard, "Règlements européens du 24 juin 2016 sur les régimes matrimoniaux et les effets patrimoniaux des partenariats enregistrés", Defrénois, nº 17, 15 septembre 2016, p. 883; N. JOUBERT, "La dernière pierre (provisoire?) à l'édifice du droit international privé europeén en matière familiale. Les règlements du 24 juin 2016 sur les régimes matrimoniaux et les effets patrimoniaux des partenariats enregistrés", RCDIP, $\mathrm{n}^{\circ}$ 1, 2017, p. 5; B. AÑovEROS TERRADAs, "El régimen conflictual de las capitulaciones en los nuevos Reglamentos de la Unión Europea en materia de regímenes económicos matrimoniales y efectos patrimoniales de las uniones registradas", Anuario Español de Derecho Internacional Privado, t. XVII, 2017, p. 832; P. WAUTELET, "What's Wrong with Article 22? The Unsolved Mysteries of Choice of Law for Matrimonial Property", Yearbook of private international law, vol. XIX, 2017-2018, p. 223; D. Coester-WaLtjen, "Connecting Factors to Determine the Law Applicable to Matrimonial Property Regimes”, Yearbook of private international law, vol. XIX, 2017-2018, p. 196; S. GodECHOT-PATRIS, "Commentaire du règlement du 24 juin 2016 relatif aux régimes matrimoniaux: le changement dans la continuité", Recueil Dalloz, 17 novembre 2016, no 39, p. 2295; E. Gallant, "Le nouveau droit international privé européen des régimes patrimoniaux de couples", Europe, mars 2017, p. 7; J. RodRíGUEz RodRIGO, Relaciones económicas de los matrimonios y las uniones registradas, antes y después de los Reglamentos (UE) 2016/1103 y 2016/1104, Tirant Lo Blanch, Valencia, 2019, pp. 33-34.

${ }^{4}$ SAP de Barcelona, de 22 marzo 2010, ECLI:ES:APB:2010:2765; SAP de Huesca, de 14 diciembre 2005 (AC 2005\2377).

${ }^{5}$ Por documento auténtico entendemos documento público otorgado ante notario. Si bien, el artículo 9.2 no exige que el notario tenga que ser español, puede ser extranjero, en cuyo caso, para hacer valer ese documento ante un juez español se deberá comprobar la legalización o apostilla del mismo y la traducción al idioma oficial español. La función del notario es, además de dar fe del acto, comprobar que la elección de ley es consentida por ambos cónyuges y no una imposición de uno sobre el otro (J. Carrascosa GonzÁlez, Matrimonio y elección de ley. Estudio de Derecho Internacional Privado, Comares, Granada, 2000, pp. 139-140).

${ }^{6}$ El concepto de residencia habitual es el que utiliza el TS español cuando interpreta el artículo 40 CC (STS 21 abril 1972, ECLI:ES:TS:1972:2317; STS 23 abril 1970 (RJ 1970\2031); STS 25 septiembre 1954, ECLI:ES:TS:1954:1081; STS 13 julio 1996 (RJ 1996\5583); STS 22 marzo 2001, ECLI:ES:TS:2001:2327; RDGRN 22 febrero 1996 (RJ 1996\3386). Así es, por residencia habitual se debe entender el lugar en el que los cónyuges se encuentran viviendo y donde quieren seguir estando. Residencia habitual es, pues, un concepto fáctico que requiere la "permanencia física" en un lugar (domus colere) y la "voluntad de permanecer" en ese sitio (animus manendi). 
12. Incluso si entendiéramos que la pareja no ha tenido residencia habitual común en Argelia, después de la celebración del matrimonio, aún nos queda la cuarta y última conexión del artículo 9.2 CC. Según indica el precepto, en última instancia, como conexión de cierre, la ley aplicable al régimen económico matrimonial será la del lugar de celebración de las nupcias; Argelia, de nuevo ${ }^{7}$.

\section{Validez de las capitulaciones matrimoniales}

13. Las capitulaciones matrimoniales son un tipo de disposición sobre el patrimonio matrimonial cuya admisibilidad y aceptación varía entre los Estados miembros (Considerando 48 del Reglamento 2016/1103). En España, por ejemplo, comprende "el negocio jurídico o contrato en el que se establecen las reglas relativas a la organización pecuniaria de las relaciones entre esposos, esto es, por medio de las capitulaciones matrimoniales, los esposos establecen las reglas relativas a su régimen económico matrimonial"s.

14. Debemos deducir de la sentencia -para que su contenido tenga sentido- que el matrimonio otorgó capitulaciones matrimoniales, cuatro después de su celebración, y en ellas se estableció que, con carácter retroactivo, su régimen económico matrimonial había sido, hasta la fecha de las capitulaciones, el de gananciales y, a partir de ese momento, el de separación de bienes.

15. Nos preguntamos en este punto cuál es la ley aplicable a la validez de las capitulaciones matrimoniales y si, conforme a esta normativa, estas podrían tener carácter retroactivo.

\section{A. Ley aplicable}

16. La ley de Argelia sería la reguladora de las capitulaciones matrimoniales otorgadas por los cónyuges en mayo de 2007; así lo indica el artículo 9.2 CC analizado previamente.

El segundo párrafo del precepto $9 \mathrm{CC}$ es la norma de conflicto aplicable para conocer la ley rectora de los efectos del matrimonio, se hayan otorgado capitulaciones matrimoniales o no. Incidimos en este aspecto porque, junto al artículo $9.2 \mathrm{CC}$, existe el precepto $9.3 \mathrm{CC}$ que alude al régimen económico matrimonial, y se plantea la duda de la relación entre ambos. Así, mientras el primero regula los efectos del matrimonio, el segundo se ocupa de la validez de los pactos o capitulaciones por los que se estipule, modifique o sustituya el régimen económico del matrimonio. La dicción de este último precepto invita

\footnotetext{
${ }^{7}$ Esta conexión de cierre, aunque en un primer momento parezca pensada sólo para que el juez tenga siempre una ley aplicable en cualquier situación -por contener una conexión cierta y que concurre en todo momento-, lo cierto es que, en el nuevo Reglamento de régimen económico matrimonial aparece como factor a tener en cuenta si los esposos quieren acordar la sumisión a determinados tribunales (art. 7). Así es, según este precepto de la norma europea, los cónyuges pueden elegir como órganos jurisdiccionales competentes, los del Estado cuya ley es la aplicable al régimen económico matrimonial, en virtud de los artículos 22 o 26.1.a) o 26.1 b), o los jueces del país de celebración del matrimonio. Por lo tanto, se utiliza como conexión útil, no como mero recurso para que el juez pueda tener una ley que aplicar en último lugar.

Tanto en el marco de la ley reguladora según el artículo 9.2 CC, como en el marco de la sumisión expresa del artículo 7 del Reglamento de régimen económico matrimonial, ofrecer ese Estado de celebración del matrimonio como opción para regir el fondo del asunto o para interponer la demanda, puede romper con el principio de previsibilidad de la ley aplicable y con el principio de cercanía del tribunal competente, puesto que, el lugar de celebración del matrimonio puede ser un lugar lejano que no guarde ninguna relación con el matrimonio en el momento de interposición de la demanda (P. QuinZÁ REDONDO, "Inscripción en el Registro de la Propiedad de una escritura de compraventa bajo régimen económico-matrimonial extranjero: La DGRN de 10 de mayo de 2017”, Bitácora Millennium DIPr., núm. 6, 2017, p. 7). No obstante, junto a esto hay que decir que, precisamente por esto, como conexión, se ubica en último lugar, y, como foro, esta posibilidad sólo se deja para que sea elegida por los cónyuges si así lo desean.

${ }^{8}$ P. Diago Diago, Pactos o capitulaciones matrimoniales en Derecho internacional privado, El Justicia de Aragón, Zaragoza, 1999, p. 27.
} 
a pensar que el artículo 9.2 CC se debería aplicar al régimen económico matrimonial legal y el precepto 9.3 CC al régimen económico matrimonial pactado9.

Sin embargo, el precepto $9.3 \mathrm{CC}$ se debe considerar una cláusula salvatoria y se debería utilizar para salvar la validez de los capítulos cuando estos no lo sean conforme a la ley a la que remite el artículo $9.2 \mathrm{CC}^{10}$. Esto es, ambos preceptos coinciden en su aplicación cuando haya capitulaciones matrimoniales, si bien, en estos casos, existe una relación de jerarquía entre ellos, de tal manera que, en primer lugar se debería aplicar el artículo $9.2 \mathrm{CC}$ y, cuando este precepto no otorgue validez a las capitulaciones, se acudiría al precepto $9.3 \mathrm{CC}$ para intentar conseguir salvar los capítulos, para conseguir que estos sean válidos conforme a alguna de las otras leyes que ofrece el artículo.

17. Aplicando, por tanto, el artículo $9.2 \mathrm{CC}$, el ordenamiento argelino sería el rector del régimen económico matrimonial de la pareja y de la validez de los capítulos otorgados por ella. Según este Derecho, "artículo 37 del Código de Familia Argelino de 9 de junio de 1984, cabe la posibilidad de que los cónyuges pacten el régimen de comunidad, conforme al cual será necesario el consentimiento de ambos esposos para la disposición de los bienes comunes" "Il. Se admite, entonces, conforme a la ley de este país, que los cónyuges puedan modificar el régimen económico del matrimonio.

Incluso, aunque el Derecho argelino no permitiera el cambio de régimen económico, el artículo 9.3 CC admite la validez de las capitulaciones matrimoniales si lo son conforme a cualquiera de las leyes que recoge el precepto. Estos ordenamientos que ofrece el artículo son la ley que rige los efectos en virtud del artículo 9.2 CC y la ley de la nacionalidad o de la residencia habitual de cualquiera de los contrayentes, en el momento del otorgamiento. Por lo tanto, como las capitulaciones matrimoniales se realizan siendo el esposo español, las mismas serían válidas conforme al Derecho español si, conforme a la ley que rige los efectos -ley argelina-, no lo fueran.

\section{B. Carácter retroactivo}

18. La siguiente cuestión que nos planteamos es si las capitulaciones otorgadas en el año 2007 pueden tener efectos retroactivos al momento de la celebración del matrimonio. La solución a esta pregunta viene determinada por la propia ley conforme a la que son válidas las capitulaciones.

19. Situándonos en el marco del Derecho español, las capitulaciones matrimoniales tienen carácter irretroactivo. Así lo considera la Dirección General de los Registros y del Notariado, aludiendo

\footnotetext{
${ }^{9}$ P. QuinZÁ Redondo, “Inscripción en el Registro de la Propiedad de una escritura de compraventa bajo régimen económicomatrimonial extranjero: La DGRN de 10 de mayo de 2017”, Bitácora Millennium DIPr., núm. 6, 2017, p. 5. Para este autor, el artículo 9.3 CC se aplica cuando existe régimen económico matrimonial pactado y el 9.2 cuando no lo hay. También se ha pronunciado en este sentido, M. Amores ConRADI, para quien "actualmente la diferencia de contenido entre los $\mathrm{n}^{\circ} 2$ y 3 del art. 9 no se encuentra en que se refieran a distintos conceptos, pues el supuesto del $n^{\circ} 3$ no es sino una fracción del de su precedente, sino en que se refieren a hipótesis distintas: que haya o no pacto específico de los cónyuges sobre su régimen económico matrimonial. Con esta ordenación, y aunque el orden seguido por el legislador sea al opuesto, lo primero que debe examinarse es si existe o no pacto entre los cónyuges, si tiene validez y con qué límites, su régimen jurídico y sólo después procederá examinar la norma más general, que viene a cumplir una función subsidiaria" (M. AMORES ConRADI, "La nueva ordenación de la ley aplicable a los efectos del matrimonio", Revista Jurídica de Castilla La Mancha, enero-agosto 1991, n 11-12, p. 43). Para este autor la explicación de que el artículo 9.3 CC remita a la ley de los efectos se encuentra en que, a través del primero, los cónyuges pueden hacer uso de la autonomía de la voluntad material y elaborar pactos que serán válidos si la ley de los efectos les da validez (vid., en este sentido, P. Diago Diago, Pactos o capitulaciones matrimoniales en Derecho internacional privado, El Justicia de Aragón, Zaragoza, 1999, pp. 228-229).

${ }^{10}$ A.L. Calvo Caravaca/J. Carrascosa González, "Los artículos 9.2 y 9.3 del Código Civil y el régimen económico matrimonial en Derecho Internacional Privado español. Valores, métodos y técnicas", Cuadernos de Derecho Transnacional, vol. 12, nº 2 , 2020, p. 209; A.L. Calvo Caravaca/J. Carrascosa González, "Efectos del matrimonio", en A.L. Calvo Caravaca/J. Carrascosa GonzÁlez (dirs.), Derecho Internacional Privado, vol. II, $17^{\mathrm{a}}$ ed., Comares, Granada, 2017, pp. 236-239; J. RodríGUez Rodrigo, Relaciones económicas de los matrimonios y las uniones registradas, antes y después de los Reglamentos (UE) 2016/1103 y 2016/1104, Tirant Lo Blanch, Valencia, 2019, pp. 112-114; RDGRN de 13 noviembre 2015, FD III y IV (JUR 2016\115973).

${ }^{11}$ RDGRN 7 noviembre 2018, FD. Primero (BOE núm. 288, 29 noviembre 2018).
} 
al artículo $1317 \mathrm{CC}$ en el que se afirma que la modificación de los capítulos no puede perjudicar los derechos ya adquiridos por terceros ${ }^{12}$. También el Tribunal Supremo español. En este sentido, "Es doctrina jurisprudencial consolidada en la interpretación del artículo 1317 del Código Civil - STS 25 de septiembre de 2007 ( RJ 2007, 5362) -, que éste despliega todos sus efectos con independencia de que pueda pedirse la declaración de ineficacia de los capitulos. Por ello se ha afirmado reiteradamente por esta Sala que no es necesario pedir la nulidad de las escrituras de capitulos matrimoniales, ya que lo que establece el artículo 1317 del Código civil es una responsabilidad "ex lege", inderogable por la voluntad de los particulares, que para nada incide en la validez de las adjudicaciones y que, en su consecuencia, no se requiere para su efectividad de declaración de ineficacia o de nulidad de clase alguna ( STS de 15 marzo 1994 [ RJ 1994, 1787] , entre muchas otras). Cuando el artículo 1317 del Código civil establece que "la modificación del régimen económico matrimonial realizada durante el matrimonio no perjudicará en ningún caso los derechos ya adquiridos por terceros" determina que los cónyuges no pueden oponerse a las ejecuciones contra los bienes que pertenecieron a la masa de los gananciales a pesar del cambio de régimen, independientemente de la declaración o no de la nulidad de los propios capitulos, siempre que se den los requisitos exigidos en el propio artículo 1317. El artículo 1317 del Código civil, completado con los artículos 1399, 1403 y 1404, determina que, al conservar los acreedores de los cónyuges sus derechos contra el cónyuge deudor, pueden dirigirse contra los bienes que formaban la masa responsable antes de las capitulaciones, con independencia de cuál de los cónyuges sea su titular después del otorgamiento de las mismas, sin que sea necesaria la declaración de nulidad o el fraude de acreedores, que constituyen otras vías distintas para obtener un resultado parecido ( SSTS 21 nov. 2005 [ RJ 2005, 7850] , 1 marzo 2006 [ RJ 2006, 1860] , 3 julio 2007 [ RJ 2007, 3792], etc.)"13.

20. Teniendo en cuenta todo lo anterior, volviendo al caso objeto del litigio, se podría afirmar el carácter retroactivo de las capitulaciones matrimoniales otorgadas por los cónyuges en el año 2007. Son dos las razones que permiten llegar a esta conclusión.

21. Por un lado, la irretroactividad se relaciona con el perjuicio a terceros. Así es, el artículo $1317 \mathrm{CC}$ considera que el cambio en las capitulaciones matrimoniales no puede perjudicar los derechos adquiridos ya por terceros. Por lo tanto, en el resto de situaciones, cuando no se alegue este daño, el nuevo régimen económico del matrimonio podría aplicarse desde el momento de la celebración del enlace. Todo ello, sabiendo, además, que los capítulos tienen naturaleza contractual y que, en este sector material prevalece la autonomía de la voluntad, la cual puede ser ejercida por las partes con las únicas limitaciones de la ley, la moral y el orden público (art. $1255 \mathrm{CC})^{14}$.

En nuestro caso, también, el cambio del régimen económico matrimonial que realizan los cónyuges es la operación inversa a la que suelen efectuar cuando su intención es ocasionar ese daño ${ }^{15}$. De esta manera, lo que los esposos hacen en el caso es convertir los bienes privativos de cada uno ellos en bienes gananciales y, por ello, pertenecientes a los dos. Esto no significa que la mutación no pueda perjudicar los derechos adquiridos por terceros. Sí podría ocasionar este perjuicio si, por ejemplo, el tercero cuenta con un bien de uno de los esposos y, por el cambio, ahora sólo puede contar con la mitad del valor de dicho bien porque ha pasado a ser ganancial y tras la disolución del régimen le corresponde la mitad

\footnotetext{
${ }^{12}$ RDGRN 16 abril 2003, FD. Segundo (RJ 2003\4035).

${ }^{13}$ STS 6 febrero 2008, RJ 2008\2661, FD. Segundo. Vid., también, en este sentido, STS 8 marzo 2012 (RJ 2012 5002), STS 5 octubre 2007 (RJ 2007\6798), STS 1 marzo 2006 (RJ 2006\1860), STS 5 octubre 2005 (RJ 2005\6915), entre otras.

${ }^{14} \mathrm{~J}$. Rodríguez Rodrigo, Relaciones económicas de los matrimonios y las uniones registradas, antes y después de los Reglamentos (UE) 2016/1103 y 2016/1104, Tirant Lo Blanch, Valencia, 2019, p. 144.

${ }^{15}$ STS 6 febrero 2008 (RJ 2008\2661), STS 8 marzo 2012 (RJ 2012\5002), STS 5 octubre 2007 (RJ 2007\6798), STS 1 marzo 2006 (RJ 2006\1860), STS 5 octubre 2005 (RJ 2005\6915). En estas sentencias del Tribunal Supremo los cónyuges hacen justo lo contrario de lo que realizan los esposos en el caso objeto de comentario. Así, lo que pactan es cambiar el régimen económico matrimonial de gananciales por uno de separación de bienes. De esta manera, los bienes que antes eran de los dos ahora pueden ser de uno de ellos, precisamente del cónyuge sin deudas, para que el otro no tenga bienes con los que pueda responder frente a sus acreedores.
} 
del valor al cónyuge que antes era propietario único del bien. En cualquier caso, si esta modificación produjera algún perjuicio a terceros, se consideraría inoponible frente a ellos.

22. Por otro lado, la aparición del Reglamento 2016/1103 en el ordenamiento español abunda en la idea de la retroactividad de las capitulaciones matrimoniales, salvo en relación con los terceros que se vieran perjudicados con el cambio.

En efecto, el artículo 22 de esta norma europea indica que el cambio de la ley aplicable al régimen económico matrimonial tendrá efectos pro futuro, a menos que haya acuerdo de los cónyuges en sentido contrario (art. 22.2) ${ }^{16}$. No obstante lo cual, si los esposos imprimen carácter retroactivo a la modificación de la ley aplicable, se acepta, pero no puede afectar negativamente a los derechos de los terceros.

El carácter prospectivo de la ley aplicable se valora de forma negativa por la doctrina porque, de esta manera, se está vulnerando el principio de unidad de ley que preside la regulación del Reglamento en esta materia de régimen económico matrimonial. Los autores piensan que sería mejor invertir la regla y establecer, como principio general, la retroactividad y, como excepción, si así lo acuerdan los cónyuges, la irretroactividad en la aplicación de la nueva ley rectora ${ }^{17}$. También hay autores que se muestran favorables a esta opción de irretroactividad del legislador, entendiendo que lo contrario podría implicar complicaciones en supuestos en los que, por ejemplo, el cambio de ley supusiera un cambio de régimen económico matrimonial y un cambio de bienes ${ }^{18}$. Además de lo anterior, respondiendo a la crítica vertida por aquellos que discrepan de la irretroactividad de la ley, en el marco del Reglamento, dicen, la protección del tercero se debe posicionar por encima del principio de unidad de ley ${ }^{19}$.

23. Por lo tanto, estamos admitiendo en nuestro ordenamiento la retroactividad de las capitulaciones matrimoniales, en algunos casos -cuando lo acuerden los cónyuges- y con ciertas limitaciones -sin perjuicio para los derechos adquiridos por terceros-. Esto supone que, por otro lado, si la ley aplicable al cambio de las mismas fuera extranjera y admitiera la retroactividad, no podríamos alegar orden público para evitar su aplicación en este punto.

\section{Otorgamiento de capitulaciones ante autoridad consular española en el extranjero}

24. En el caso objeto de comentario se alude a otra cuestión, si bien de menor importancia, que merece también ser explicada.

25. Según indica la sentencia, las capitulaciones matrimoniales se otorgan ante el Cónsul General de España en Argel, se realizan, por tanto, ante autoridad consular española en el extranjero. Esto no significa, necesariamente, que los capítulos deban regirse por el derecho español; se pueden otorgar ante autoridad española y que se encuentren regulados por Derecho extranjero. Lo que sí implica este hecho es que la forma de celebración del negocio jurídico deba ser la española (art. 11.3 CC) ${ }^{20}$.

${ }^{16}$ H. Péroz/E. Fongaro, Droit international privé patrimonial de la famille, $2^{\mathrm{a}}$ ed., Lexis Nexis, Paris, 2017, p. 199; L. RADEMACHER, "Changing the past: retroactive choice of law and the protection of third parties in the European Regulations on patrimonial consequences of marriages and registered partnerships", $C D T$, vol. 10, $\mathrm{n}^{\circ}$ 1, p. 15; S. GoDECHOT-PATRIS, "Commentaire du règlement du 24 juin 2016 relatif aux régimes matrimoniaux: le changement dans la continuité", Recueil Dalloz, 17 novembre 2016, n 39, p. 2295.

${ }^{17}$ P. QuinzÁ Redondo, Régimen económico matrimonial. Aspectos sustantivos y conflictuales, Tirant lo Blanch, Valencia, 2016, p. 360 .

${ }^{18}$ B. AÑoveros terRadas, "El régimen conflictual de las capitulaciones en los nuevos Reglamentos de la Unión Europea en materia de regímenes económicos matrimoniales y efectos patrimoniales de las uniones registradas", Anuario Español de Derecho Internacional Privado, t. XVII, 2017, p. 836.

${ }^{19}$ B. AÑoveros terradas, "El régimen conflictual de las capitulaciones en los nuevos Reglamentos de la Unión Europea en materia de regímenes económicos matrimoniales y efectos patrimoniales de las uniones registradas", Anuario Español de Derecho Internacional Privado, t. XVII, 2017, p. 836.

${ }^{20}$ A.L. Calvo Caravaca/J. Carrascosa González, "Los artículos 9.2 y 9.3 del Código Civil y el régimen económico matrimonial en Derecho Internacional Privado español. Valores, métodos y técnicas”, Cuadernos de Derecho Transnacional, vol. $12, \mathrm{n}^{\mathrm{o}} 2,2020$, p. 223. 
26. Por lo tanto, tal como indica el artículo $1327 \mathrm{CC}$, las capitulaciones matrimoniales deberán constar en escritura pública. Por esta razón, el Cónsul español en Argel actúa ejerciendo funciones de notario (FD Tercero). De este modo, las capitulaciones matrimoniales son válidas desde el punto de vista formal.

\section{Publicidad registral}

27. Por último, igualmente es interesante hacer referencia a la publicidad que supone la inscripción del bien inmueble en el Registro de la Propiedad. En este sentido, en primer lugar, debemos recordar la distinción entre la ley que regula la publicidad del Registro y la ley que regula el régimen económico matrimonial. La primera de ellas sería la española, si en España se ubica el Registro donde se encuentra la inscripción del bien inmueble (art. 10.1 CC) -lex registrationis o lex loci-21. La segunda será la determinada por las normas de producción interna españolas -en casos de matrimonios celebrados antes del 29 de enero de 2019 y de elecciones de ley realizadas antes de esa fecha- o por el Reglamento de régimen económico matrimonial -en el resto de los casos-.

28. Según indica el Derecho español, en relación con los bienes inmuebles que se encuentran inscritos en el Registro de la Propiedad nacional, debe constar el régimen económico matrimonial del que aparece como adquirente, siempre que se trate de un régimen previsto en el Derecho civil español $(\text { art. } 90 \mathrm{RH})^{22}$. En este caso, por el principio iura novit curia, se deberá hacer mención a las cuotas de propiedad del bien que posee cada uno de los esposos.

Sin embargo, si el Derecho rector del régimen económico matrimonial es un ordenamiento extranjero, el operador jurídico no tiene por qué conocer el contenido del mismo y, por ello, la DGRN permite que en la inscripción se indique de manera genérica que la propiedad del bien queda sujeta al régimen económico matrimonial -extranjero- correspondiente.

En los parágrafos siguientes estudiaremos con más detalle lo que acabamos de resumir aquí, en el supuesto particular objeto de la sentencia que se está comentando en este trabajo, esto es, en el caso de bienes inmuebles situados en España e inscritos en el Registro de la Propiedad nacional.

\section{Inmuebles situados en España y ley española rectora del régimen económico matrimonial} (art. $90 \mathrm{RH})$. En relación con inmuebles situados en España y que se encuentran inscritos en el Registro de la Propiedad, el tercero podrá saber cuál es el régimen económico del matrimonio que ha adquirido ese bien, si el mismo está regulado en el Código civil español; puesto que, en la inscripción se deberá hacer constar este dato.

Así es, el artículo 90 del Reglamento Hipotecario dispone que "1. Los bienes que con arreglo al Derecho foral o especial aplicable correspondan a una comunidad matrimonial, se inscribirán a nombre del cónyuge o de los cónyuges adquirentes, expresándose, cuando proceda, el carácter común $y$, en su caso, la denominación que aquélla tenga. Si los bienes estuvieren inscritos a favor de uno de los cónyuges y procediera legalmente, de acuerdo con la naturaleza del régimen matrimonial, la incorporación o integración de los mismos a la comunidad, podrá hacerse constar esta circunstancia por nota marginal. 2. Los bienes adquiridos por ambos cónyuges, sujetos a cualquier régimen de separación o participación, se inscribirán a nombre de uno y otro, en la proporción indivisa en que adquieran conforme al artículo 54 de este Reglamento. 3. Si el régimen económico-matrimonial vigente fuera el de participación se hará constar el consentimiento del cónyuge del disponente si resultare del título y la

${ }^{21}$ J. Carrascosa González, "Derechos reales”, en A.L. Calvo Caravaca/J. Carrascosa González (dirs.), Derecho Internacional Privado, vol. II, $18^{\mathrm{a}}$ ed., Comares, Granada, 2018, p. 1218; E. CAstellanos Ruiz, "Adquisición y transmisión de bienes inmuebles por matrimonios entre extranjeros: Su inscripción en el registro de la propiedad”, Derecho Privado y Constitución, $\mathrm{n}^{\circ} 33,2018$, p. 18.

${ }^{22}$ Decreto de 14 de febrero de 1947 por el que se aprueba el Reglamento Hipotecario, BOE núm. 106, de 16 abril 1947. 
disposición fuera a título gratuito". También el artículo 51.9.a) RH y el artículo 159 del Reglamento notarial hacen referencia a esto ${ }^{23}$.

30. Inmuebles situados en España y ley extranjera rectora del régimen económico matrimonial (art. $92 \mathbf{R H}$ ). En los supuestos en los que la legislación aplicable al régimen económico matrimonial fuera extranjera, el artículo 92 RH permite al registrador que inscriba la adquisición con sujeción a $s u$ [del alquirente o de los adquirentes] régimen económico matrimonial.

Así, según el precepto, "Cuando el régimen económico-matrimonial del adquirente o adquirentes casados estuviere sometido a legislación extranjera, la inscripción se practicará a favor de aquél o aquéllos haciéndose constar en ella que se verifica con sujeción a su régimen matrimonial, con indicación de éste, si constare"24.

31 Por lo tanto, la mención genérica a la que alude el precepto sólo podría producirse cuando el registrador supiera que el régimen económico matrimonial del adquirente se encuentra regido por un Derecho extranjero.

Así, cuando los dos cónyuges adquirentes sean extranjeros, la primera conexión del artículo 9.2 CC determinará que la ley aplicable a su régimen económico matrimonial sea un ordenamiento extranjero $^{25}$. Es, en estos casos, en los que el registrador puede hacer esa mención genérica e inscribir con sujeción a su régimen matrimonial ${ }^{26}$. En estas circunstancias, además, se debería probar -a posteriori- el Derecho extranjero que regule, finalmente, el régimen patrimonial ${ }^{27}$.

32. El artículo $92 \mathrm{RH}$ flexibiliza la regla registral en virtud de la cual debe constar claramente la extensión de los derechos inscritos, tal como prescribe el artículo $51.6 \mathrm{RH}$, así como el régimen económico matrimonial, en caso de que el adquirente esté casado y el acto o contrato afecte a la sociedad conyugal (art. 51.9.a) RH). El artículo $92 \mathrm{RH}$, por tanto, cuando la ley aplicable a los efectos económicos del matrimonio sea un ordenamiento extranjero, permite no hacer constar en la inscripción ese régimen económico matrimonial aplicable ${ }^{28}$.

En estos supuestos, es verdad que el encargado del Registro puede no conocer el contenido del Derecho extranjero correspondiente, pero ello no le eximiría de tener que determinar cuál es ese ordenamiento, por aplicación imperativa de la norma de conflicto española correspondiente (art. 12.6 CC). En el Registro de la Propiedad, por tanto, debería aparecer la ley que rige el régimen económico matrimo-

${ }^{23}$ Decreto de 2 junio de 1944 por el que se aprueba con carácter definitivo el Reglamento de la organización y régimen del Notariado, BOE núm. 189, de 7 julio 1994.

${ }^{24}$ RDGRN de 2 abril 2018 (RJ 2018\1496); RDGRN 19 octubre 2018 (RJ 2018\4825).

${ }^{25}$ RDGRN 2 abril 2018 (RJ 2018\1496).

${ }^{26}$ P. QuinZÁ Redondo, "Inscripción en el Registro de la Propiedad de una escritura de compraventa bajo régimen económicomatrimonial extranjero: La DGRN de 10 de mayo de 2017”, Bitácora Millennium DIPr., núm. 6, 2017, p. 12.

Esta posibilidad que ofrece el legislador español tiene varias excepciones (P. QUINZÁ REDONDO, "Inscripción en el Registro de la Propiedad de una escritura de compraventa bajo régimen económico-matrimonial extranjero: La RDGRN de 10 de mayo de 2017”, Bitácora Millennium DIPr., núm. 6, 2017, p. 11; E. Castellanos Ruiz, "Adquisición y transmisión de bienes inmuebles por matrimonios entre extranjeros: Su inscripción en el registro de la propiedad”, Derecho Privado y Constitución, $\mathrm{n}^{\circ} 33$, 2018, pp. 29 y ss). Así, si se trata de inscribir partes indivisas de una finca o derecho y el registrador conociere el régimen de separación de bienes que une a los cónyuges, deberá precisar la porción de cada condueño en el momento de la inscripción; haciendo prevalecer, así, el artículo 54 RH (RDGRN de 19 de diciembre de 2003 (RJ 20041234); RDGRN 4 febrero 2004 (RJ 2004\1995); RDGRN 12 febrero 2004 (RJ 2004\2000); RDGRN 19 octubre 2018 (RJ 2018\4825); RDGRN 1 marzo 2019 (RJ 2019\1423). En todos estos casos citados de la DGRN -salvo en el último-, los cónyuges eran británicos). Por otro lado, cuando se trata de un régimen de comunidad de bienes y uno de los cónyuges adquiere el bien como privativo (E. CASTELLANOS RuIz, "Adquisición y transmisión de bienes inmuebles por matrimonios entre extranjeros: Su inscripción en el registro de la propiedad", Derecho Privado y Constitución, no 33, 2018, pp. 33 y ss.; RDGRN 3 mayo 2016 (RJ 2016\3007); RDGRN de 10 de mayo de 2017 (RJ 2017 2351).

${ }^{27}$ P. Quinzá Redondo, “Inscripción en el Registro de la Propiedad de una escritura de compraventa bajo régimen económicomatrimonial extranjero: La DGRN de 10 de mayo de 2017”, Bitácora Millennium DIPr., núm. 6, 2017, pp. 4-5.

${ }^{28}$ Todo ello está muy bien explicado en la RDGRN de 2 abril 2018 (RJ 2018\1496) y en la RDGRN de 1 marzo 2019 (RJ 2019\1423) 
nial del sujeto que adquiere el bien en cuestión ${ }^{29} ; \mathrm{y}$, en caso de disparidad en lo inscrito en el Registro Civil y en el Registro de la Propiedad, prevalecería, en esta materia, lo recogido en este último ${ }^{30}$. Sin embargo, como acabamos de mencionar, primero la DGRN y después el artículo $92 \mathrm{RH}$-en la reforma de 1982-, permiten que esto no sea así y que no se deba determinar qué Derecho extranjero es el rector del régimen económico matrimonial del adquirente en el momento de la adquisición ${ }^{31}$.

Así es, la DGRN ha mantenido la tesis según la cual se puede diferir al momento de la enajenación del inmueble la determinación del régimen económico matrimonial. En el Registro se hará la mención de la adquisición con sujeción a su régimen matrimonial y, con posterioridad, se fijará cuál es ese régimen económico matrimonial ${ }^{32}$. Así lo recoge expresamente, por ejemplo, en la Resolución de 7 de marzo de 2007: "El recurso ha de ser estimado. Cuando se trata de adquisiciones realizadas por cónyuges extranjeros, la doctrina de este Centro Directivo, elaborada, entre otras, por las Resoluciones citadas en los "Vistos», consiste en que no es exigible la determinación del régimen matrimonial, pues resulta más eficaz diferir tal determinación para el momento de la enajenación. Por ello, el artículo 92 del Reglamento Hipotecario ( RCL 1947, 476 y 642) establece que, en este caso, la inscripción se hará a favor de los adquirentes «con sujeción a su régimen matrimonial». El mismo artículo permite que se haga la inscripción, pues sólo exige que se exprese el régimen en el Registro si el mismo constare".

33. No obstante lo anterior, como acabamos de referir, el propio artículo $92 \mathrm{RH}$ indica que esa mención genérica podrá practicarse salvo que constara cuál es el régimen económico matrimonial al registrador. Por lo tanto, si el encargado del Registro conoce el contenido del Derecho extranjero aplicable, deberá indicar en la inscripción cuál es este.

Para determinar ese contenido de la ley aplicable a los efectos económicos del matrimonio, el notario puede aplicar su conocimiento privado al respecto, al menos eso es lo que puede deducirse del artículo 36 del $\mathrm{RH}^{33}$. Efectivamente, aunque este precepto alude al conocimiento privado del registrador en relación con las formas y solemnidades extranjeras y a la aptitud y capacidad legal necesarias para el acto, la DGRN y la jurisprudencia menor extiende esa posibilidad, también, al contenido de la ley rectora del régimen económico matrimonial ${ }^{34}$.

\footnotetext{
${ }^{29}$ RDGRN 2 abril 2018 (RJ 2018\1496).

${ }^{30}$ L.F. Carrillo Pozo, "Eficacia en España de las resoluciones extranjeras en materia de efectos económicos del matrimonio", $C D T$, vol. $4, \mathrm{n}^{\circ}$ 1, marzo 2012, pp. 107-108.

${ }^{31}$ RDGRN 2 abril 2018 (RJ 2018\1496).

${ }^{32}$ RDGRN 7 marzo 2007 (RJ 2007\1576). Vid,, también, RDGRN 5 marzo 2007 (RJ 2007\6141); RDGRN 3 enero 2003 (RJ 2003 2182); RDGRN 26 febrero 2008 (RJ 2008\2100); RDGRN 3 febrero 2014 (RJ 2014\1974).

Vid., criticando esta posición de la DGRN, C. Mingorance GonsÁlvez, "Registro de la propiedad y régimen económico de los matrimonios extranjeros en España", Revista de Derecho Privado, mayo-junio 2010, pp. 64-65, 67-68; L.F. CARRILLO Pozo, "Eficacia en España de las resoluciones extranjeras en materia de efectos económicos del matrimonio", CDT, vol. 4, nº 1, marzo 2012, pp. 106-107.

${ }_{33}$ P. Diago Diago, "La publicidad del régimen económico matrimonial y la protección de terceros en Derecho Internacional Privado español”, Boletín de Información del Ministerio de Justicia, núms. 2067-2068, año 2008, p. 2767.

Artículo 36 RH: "los documentos otorgados en territorio extranjero podrán ser inscritos si reúnen los requisitos exigidos por las normas de Derecho Internacional Privado, siempre que contengan la legalización y demás requisitos necesarios para su autenticidad en España. La observancia de las formas y solemnidades extranjeras y la aptitud y capacidad legal necesarias para el acto podrán acreditarse, entre otros medios, mediante aseveración o informe de un Notario o Cónsul español o de Diplomático, Cónsul o funcionario competente del país de la legislación que sea aplicable. Por los mismos medios podrán acreditarse la capacidad civil de los extranjeros que otorguen en territorio español documentos inscribibles. El Registrador podrá, bajo su responsabilidad, prescindir de dichos medios si conociere suficientemente la legislación extranjera de que se trate, haciéndolo así constar en el asiento correspondiente".

${ }^{34}$ SAP Alicante 15 diciembre 2005 (JUR 2006\129499); RDGRN 19 diciembre 2003 (RJ 2004|234); RDGRN 4 febrero 2004 (RJ 2004\1995); RDGRN 28 octubre 2015 (RJ 2015\6046); RDGRN 15 febrero 2016 (RJ 2016\1741). Según esta última resolución, las normas sobre prueba del Derecho extranjero por órganos judiciales -el artículo 33 de la LCJIMC-, son generales y ceden frente a la aplicación de una regulación especial como puede ser la existente en relación con la aplicación extrajudicial -registral- del Derecho extranjero; prevista, esta última, en el artículo 36 RH (vid., también, E. CAstellanos Ruiz, "Adquisición y transmisión de bienes inmuebles por matrimonios entre extranjeros: Su inscripción en el registro de la propiedad", Derecho Privado y Constitución, no 33, 2018, p. 31).

SAP Alicante 15 diciembre 2005: "la literalidad del precepto establece la indicación del régimen económico matrimonial «si constare», no concretando si esta constancia, debe estar referida al Notario que autoriza la escritura o al Registrador
} 
34. Debemos distinguir, en todo lo expuesto en este epígrafe, entre la determinación del Derecho aplicable y la concreción del contenido del mismo. En el caso que acabamos a analizar, el Derecho aplicable se sabe que debe ser extranjero. Es más, aplicando la norma de conflicto correspondiente, el registrador debe conocer de qué derecho extranjero se trata. Sin embargo, lo que el artículo 92 RH permite es que no conste en la inscripción cuál es ese ordenamiento jurídico aplicable al régimen económico matrimonial, sabiendo, repetimos de nuevo, que debe ser uno extranjero.

Esto es, con la mención genérica de que la adquisición se realiza con sujeción al régimen económico matrimonial, el tercero sabe que la ley aplicable al mismo es un Derecho extranjero, pero no conocerá de qué ordenamiento extranjero se trata -ni su contenido, por supuesto-.

Este hecho es criticable desde el momento en que el registrador está obligado a aplicar la norma de conflicto correspondiente y, por tanto, debe conocer el Derecho extranjero aplicable al régimen económico matrimonial; cuestión diferente es exigirle el conocimiento del contenido del mismo, el principio iura novit curia lo impide.

Por lo tanto, distinguiendo entre el Derecho extranjero aplicable y el contenido concreto del mismo, entendemos que este último se pueda diferir a un momento posterior -el de la enajenación del bien-, sin embargo, la determinación de cuál sea la legislación extranjera aplicable debería constar en la inscripción, primero, porque el registrador debería conocerla, y segundo, porque puede beneficiar a los terceros que conozcan el contenido de la misma.

35. En el caso en cuestión, en el Registro aparece que el bien se ha adquirido perteneciendo el $100 \%$ del pleno dominio a $D^{a}$ Virginia y a D. Jacobo, por título de adjudicación administrativa con carácter presuntivamente ganancial (folio 28) (FD Tercero), con lo cual, debemos entender que el registrador ha considerado que el Derecho aplicable al régimen económico matrimonial es el español y no el argelino. Este hecho nos lleva a pensar en que se ha incurrido en error, puesto que, como ya se ha expuesto anteriormente, según el artículo 9.2 CC, la rectora de los efectos debe ser la argelina -separación de bienes, por tanto-. Y, por otro lado, las capitulaciones matrimoniales, con las que podríamos entender que los cónyuges cambian la ley aplicable a su régimen económico del matrimonio con carácter retroactivo y hacen prevalecer la sociedad de gananciales, se otorgan después de la inscripción del bien en el Registro de la Propiedad.

Por todo ello, podemos deducir que se ha ignorado el elemento de extranjería en el caso y se ha resuelto la solicitud de inscripción aplicando el Derecho español como si el supuesto fuera interno.

\footnotetext{
de la Propiedad que la califica y la inscribe, pero la interpretación no puede realizarse como pretende el apelante, referida únicamente al título, así en caso de que el Notario tuviese constancia del régimen matrimonial de los adquirentes sometidos a legislación extranjera deberá hacerlo constar en la escritura, la constancia del régimen matrimonial extranjero no debe quedar limitada sólo al Notario sino que es también extensiva al Registrador de la Propiedad en virtud de la responsabilidad que asume en la inscripción del título, debiendo ser confirmada la sentencia de instancia en los argumentos expuestos en la misma en relación a la mención del régimen económico matrimonial, siendo por tanto aplicable el artículo 36 del RH ( $R C L$ 1947, 476 y 642) pues conforme al artículo 9.2 del CC (LEG 1889, 27) el régimen económico matrimonial está dentro de las cuestiones relativas a las personas, debiendo ser rechazada la alegación del apelante, de que el artículo 36 es únicamente aplicable a documentos inscribibles otorgados por extranjeros en territorio español en relación a la capacidad de las personas y no al régimen económico matrimonial”.
} 